\title{
Dutch speech intelligibility in bilingual Turkish-Dutch children in Flanders
}

\author{
Ellen Simon, Evelien D’haeseleer, Feyza Altinkamis, and \\ Koen Plevoets \\ Ghent University
}

This study examines the Dutch intelligibility of a group of monolingual Dutch and bilingual Turkish-Dutch preschool children in Flanders, as rated by native Dutch listeners and measured by a Dutch intelligibility test. The intelligibility of the bilingual children is compared to that of the monolingual Dutch children, in order to examine whether age and/or task effects are similar or different in the two groups. The results revealed that intelligibility was affected by age, but showed no significant interaction between age and group. However, we found a significant interaction between age and task: children's intelligibility increased with age for a word production as well as a sentence production task, but much more so for the latter than for the former. We discuss the results in relation to the children's developing phonological systems, the age of exposure to Dutch and the nature of the test.

Keywords: intelligibility, early bilingualism, Turkish, Dutch, second language acquisition, age effect, task effect, exposure

\section{Introduction}

Speech intelligibility has always played a central role in research on children with a speech impairment, since the main goal of treatment in these children is generally to increase their overall speech intelligibility (Baudonck, Buekers, Gillebert, \& Van Lierde, 2009). More recently, the notion of intelligibility has also been gaining interest in the field of bilingual and second language acquisition. With increased globalization there has been a parallel increase in people's mobility and consequently also an ever growing number of people, who - for various reasons are growing up bilingually or are learning a second language at an early age. Fluent communication and mutual intelligibility have replaced the goal of a nativelike pronunciation and are now at the heart of foreign language learning (Jenkins, 
2000). Despite the growing importance attached to intelligibility in these fields, very little is known about the intelligibility of young children growing up simultaneously or sequentially with two languages.

The main aim of this study is to characterize the speech intelligibility of bilingual children, more specifically bilingual Turkish-Dutch children in Flanders, in the north of Belgium. Flanders has a large Turkish-speaking community, with a strong presence in Ghent, a middle-sized town of about 250,000 inhabitants. Immigration from Turkey started around 1964 and has come in several larger flows. Previous research has shown that in this population with a migration background from Turkey, the Turkish language has largely been preserved as the home language, which is felt to be strongly linked to the families' identity (Altinkamis \& Agirdag, 2014). As a result, many children grow up with Turkish as their home language and are first massively exposed to Dutch when they start attending daycare or preschool.

For young children, preschool and primary school teachers are often the first to report intelligibility or more general communication problems with children in their classroom. In consultation with the parents, the child is then either sent to a speech therapist or it is decided to wait till the child gets older. As Thordardottir, Rothenberg, Rivard and Naves (2006, p. 2) write, "[a] basic premise of clinical identification of developmental language disorders is comparison with normal developmental patterns". It is precisely this lack of normal developmental patterns in speech intelligibility of bilingual children which has created a situation of uncertainty, in which some bilingual children with speech impairments are not sent to speech therapists or too late, and others who do not have a speech impairment, are mistakenly advised to start speech therapy. Indeed, there have been reports of both under- and overdiagnosis of speech impairment in bilingual children (De Jong, Cavus, \& Baker, 2010; De Smedt, Roeyers, \& Schelpe, 2017, see also Boerma \& Blom, 2017 on methods of testing bilingual children for developmental language disorders). The present study is a first step to characterize Dutch speech intelligibility in a group of bilingual Turkish-Dutch children in Flanders. The main aim of the study is to examine the effect of age and task on the Dutch intelligibility of this group of bilingual children. We include data from a group of monolingual children, in order to compare the impact of these factors on speech intelligibility in the two language groups (see Section 3 below). 


\section{Review of the literature}

2.1 Measuring intelligibility: A multitude of factors affecting the intelligibility of speech

As noted by Kang, Thomson and Moran (2018), there is no general agreement on how speech intelligibility is best measured and even defining the concept has proven to be problematic. In this paper, we follow Munro and Derwing (1995) in defining intelligibility as "the extent to which a speaker's message is actually understood by the listener" (p.76). It is in this sense crucially different from what is sometimes termed 'perceived comprehensibility' (Munro \& Derwing, 1995), which refers to the extent to which listeners report speech to be intelligible. Perceived comprehensibility refers to listeners' perceptions, which can be measured through Likert-scale responses by listeners (see e.g. Munro \& Derwing, 1995). Intelligibility refers to the actual recognition of speech sounds and is typically measured as the accuracy of transcriptions of produced speech.

This does not mean, however, that intelligibility is an objective characteristic of speech, independent of the listener or the context. As Kent and Miolo (1994, p.81) point out, "intelligibility is rooted in characteristics of a speaker-listener dyad and the conditions of their communication". As such it is influenced not only by the nature of the spoken material, such as the length of the utterance, and the context (e.g. the availability or lack of visual cues from the speaker), but also by the extent to which the listener is familiar with the speaker's speech and the support from the context (Kent \& Miolo, 1994, p. 81).

The language background of the speakers and listeners has, for instance, been shown to play a major role in determining the intelligibility of speech. Studies by Bent and Bradlow (2003) and Munro and Derwing (1995) have shown that for native listeners native speech is in general more intelligible than non-native speech. Bent and Bradlow (2003) also observed an 'interlanguage speech intelligibility benefit' (ISIB), i.e. non-native listeners were as accurate at recognizing words produced by a high-proficiency non-native speaker with whom they shared the native language as they were at recognizing words produced by a native speaker. The ISIB was further tested by Hayes-Harb, Smith, Bent and Bradlow (2008), who distinguish between an ISIB for talkers (ISIB-T) and an ISIB for listeners (ISIB-L). ISIB-T is defined as the process whereby non-native listeners may find non-native talkers more intelligible than they do native talkers, while ISIB-L refers to the process whereby non-native listeners outperform native listeners in recognizing non-native-accented speech.

Besides language background, attitudinal factors are also known to play a role in speech intelligibility (Rajadurai, 2007). A recent study by Babel and Russell 
(2015) showed that speech intelligibility decreased when listeners where shown a picture of an ethnically Chinese Canadian speaker compared to when no visual prime was presented. This effect was not found for speakers identifying as White Canadians, suggesting that listeners associate Chinese faces with less intelligible, non-native accents. On-going projects are further examining the extent to which intelligibility is influenced by listeners' attitudes towards the perceived ethnicity of the speakers (Vasandani, Babel, \& Munson, 2018). In the current study, the potential effect of listeners' attitudes was kept to a minimum by not informing listeners on the language background of the child they were listening to (bilingual TurkishDutch or monolingual Dutch) and by presenting only auditory stimuli rather than video recordings (see Section 4 for details on the method).

\subsection{Phonological development and intelligibility in bilingual children}

Cumulative research on phonological development in bilingual children reports on both acceleration of phonological development in bilinguals compared to monolinguals, resulting from positive transfer of cross-linguistic knowledge, and deceleration, resulting from negative cross-linguistic transfer (cf. studies reviewed by Core and Scarpelli, 2015). Core and Scarpelli (2015, p.102) note that any comparison between the phonological development of monolingual and that of bilingual children is made difficult by the influence of various factors, including age of exposure to each language, relative amount of exposure to each language and proficiency in each language. Especially in young children, the child's age may play an important role: an older bilingual child for whom the home and the school language are different will have been speaking the school language for a longer time than a younger child and is thus more likely to score higher on standardized tests and to achieve similar accuracy levels to monolingual peers (Core \& Scarpelli, 2015, p.105).

To date, few studies have measured speech intelligibility of bilingual children and to our knowledge, no previous studies have examined the intelligibility of bilingual children with Dutch as one of their languages. Prezas, Hodson and Schommer-Aikins (2014) examined perceived comprehensibility in English and Spanish of 60 bilingual preschool children of Mexican descent with Spanish as their primary home language. The children ranged in age from 4;0 to 5;10. Listeners not familiar with the children (or the children's speech) were asked to rate the comprehensibility on a Likert scale from 1 to 5 . For each child, a phonological deviation score, a receptive vocabulary score and a mean speech rate were obtained. Phonological deviation and vocabulary scores predicted comprehensibility ratings in English. Perceived comprehensibility in Spanish was predicted by phonological deviation scores, followed by speech rate. The results also revealed 
that five-year-old bilingual children were perceived to be significantly more comprehensible than four-year-old bilinguals.

\section{The present study}

In the present study, we focus on the intelligibility of a group of three- to sixyear old Turkish-Dutch bilingual children, which we compare to the intelligibility of a group of monolingual Dutch children in the same age range. The main aim is to examine the intelligibility at word, sentence and narrative levels of a group of bilingual Turkish-Dutch preschool children, as rated by unfamiliar listeners. The intelligibility of the bilingual children will be compared to that of monolingual Dutch children, in order to examine whether age and/or task effects are similar or different in the two groups. To address these issues, we tested bilingual Turkish-Dutch and monolingual Dutch children on their intelligibility in Dutch, as measured by the Dutch intelligibility test 'Percentage Spraakverstaanbaarheid' (henceforth PSv, Percentage Speech Intelligibility in Children; Buekers, Dekelver, \& Zoons, 2005, see Section 4.2.). We opted for this test, because it is a test frequently used by speech therapists in Flanders and it is the only normed test available for measuring speech intelligibility in children in Flanders. We address the following two research questions (RQ's):

RQ1. Does intelligibility increase with age for bilingual and monolingual 3- to 6-year-old children and if so, does age affect intelligibility differently for the two language groups?

RQ2. To what extent are differences in intelligibility rates between bilingual and monolingual children dependent on the task (word production, sentence production and story-telling tasks) through which intelligibility is measured?

On the basis of the literature reviewed above, we posit the following hypotheses:

Hypothesis 1: In both language groups, there will be an effect of age, in that the older children will be more intelligible than the younger ones (Hypothesis 1a). We also predict an interaction between age and language background, in that the difference between the monolingual and bilingual children will be smaller for older than for younger children (Hypothesis $1 \mathrm{~b}$ ). This last hypothesis is based on the fact that the older bilingual children have been exposed to Dutch at school for a longer period of time than younger children, who have spent relatively more time in the home environ- 
ment, where they are mostly immersed in Turkish. Earlier studies (Core \& Hoff, 2012; Scarpelli \& Core, 2014, discussed in Core \& Scarpelli, 2015) have shown that relative exposure to each language in bilingual children affects phonological abilities in that language, at least for toddlers (22-30 months), whose relative exposure to English and Spanish was directly related to nonword repetition accuracy in these two languages. As such, children in the current study who have received more exposure to Dutch can be predicted to have more developed phonological abilities in that language and to be more intelligible than children with less exposure.

Hypothesis 2: We predict that the intelligibility rates of the bilingual children will be lower than those of the monolingual children for the sentence production and story-telling task, but not for the word production task (see Section 4.2. for details). This hypothesis is based on the results of previous studies which have shown that, in general, accented speech is less intelligible to native listeners than non-accented speech (Munro \& Derwing, 1995; Bent \& Bradlow, 2003, see Section 2.1). Since young children with Turkish as a home language have been less exposed to Dutch than monolingual peers at the time when they are tested, some bilingual children are likely to transfer phonological elements from Turkish to Dutch and are expected to produce Turkish-accented Dutch. The ISIB-L (Hayes-Harb et al., 2008, see 2.1 above) suggests that if the bilingual children produce Turkish-accented Dutch, they will be less intelligible than monolingual Dutch children to a group of native Dutch listeners. The shared native language between the native Dutch listeners and the native Dutch child talkers may lead to higher intelligibility rates for the monolingual than for the bilingual children. We hypothesize that the difference between the two groups will be greater in the cognitively more demanding sentence production task, where children need to be able to process and repeat the sentences, and in the story-telling task, where they need both lexical and syntactic knowledge as well as narrative skills. The difference may not reach significance in the word production task, where children can store the acoustic signal in their short term memory and imitate it, possibly with less influence from their Turkish phonological system. 


\section{Methodology}

\subsection{Participants}

\subsubsection{Speakers}

A total of 96 children were tested, 8 of whom were excluded because of insufficient recording quality (background noise) or technical failure of the equipment. An additional 8 children were excluded because one of the parents was a native speaker of Dutch $(N=5)$ or because they had an additional home language besides Turkish or Dutch $(N=3)$. The remaining 80 children (46 girls and 34 boys) were included in the study: 43 monolingual Dutch and 37 bilingual Turkish-Dutch children. The children were three- to six-years old $(\min .=3 ; 3$; $\max .=6 ; 11)$, with a mean age of 60 months or 5; (monolingual group: $M=60$ months; bilingual group: $M=61$ months). Figure 1 presents a histogram of the children's age in each language.

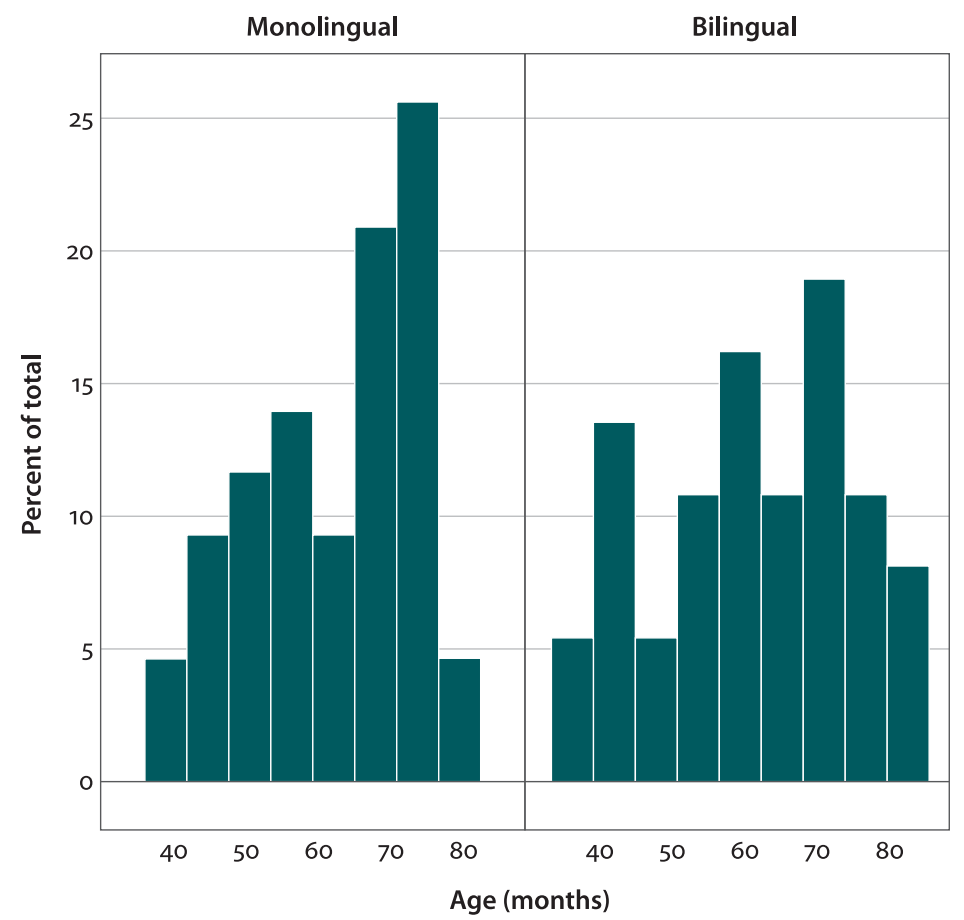

Figure 1. Histogram of age in monolingual and bilingual children

The children were recruited in six different schools in Ghent, a town in Flanders in the north of Belgium. Personal background information (age, home language, gender) was obtained through a short questionnaire, completed by the 
parents or teachers. By recruiting bilingual and monolingual children attending the same schools, we aimed to avoid large differences between the group of monolingual and that of bilingual children in terms of socio-economic status. Consent to use the data for academic purposes was obtained from the parents or the school heads.

The majority of the children's parents $(N=61$, Mono: $N=31$; Bi: $N=30)$ completed a more comprehensive questionnaire or interview on the socio-economic status of the families and - for the bilingual children - on the children's exposure to and use of Dutch and Turkish. The parents of the remaining children $(N=19)$ either preferred not to provide additional information or could not be reached. The highest qualification of the mother was used as an indicator of socioeconomic status and differed slightly between the two language groups: in the 31 monolingual families who completed the questionnaire, 28 mothers had a degree in tertiary education, 2 in in secondary education and 1 in primary education. In the 30 bilingual families who completed the questionnaire, 14 mothers had a degree in tertiary, 12 in secondary and 4 in primary education. It should in this context be noted that socio-economic status is known to play a role in children's general language development (e.g. Hoff, 2006 for a comprehensive discussion), though it may have a stronger impact on, for instance, lexical development than on phonological development and hence speech intelligibility. ${ }^{1}$

A total of 30 mothers of bilingual families were interviewed on the amount of exposure to and use of Turkish and Dutch by the child. Together with the mother, the interviewer (third author of this paper) completed a 27 -items questionnaire about the language used by the child in interactions with various relatives, the language used in interaction with the child, the language used among family members and the language used at home during a set of activities, such as watching television. The language exposure and use was indicated on a scale from 1 ('only Turkish') to 7 ('only Dutch'), with 4 defined as '50\% Dutch and 50\% Turkish). For each child, an average score, ranging from 1 to 7 , was then calculated. The mean score for all children was 2.8 (s.d. 1.02, min. 1.42, max. 5.08), suggesting on average more exposure to and use of Turkish than of Dutch. Twenty-six out of thirty mothers $(87 \%)$ indicated that the child's language used at home was Turkish at least $50 \%$ of the time. The remaining 4 children used more Dutch than Turkish at home. As such, even though the children's parents' first language was Turkish, the children were also exposed to Dutch to different extents (be it in interactions with their parents, siblings or through the media) and the children's bilingual setting

1. A study on the phonological development of 624 British English-speaking children showed no significant effects of socio-economic status on any of the phonological accuracy measures (Dodd, Holm, Hua, \& Crosbie, 2003). 
was situated somewhere on the continuum between bilingual first and second language acquisition (cf. the distinction between bilingual first and second language acquisition, 'BFLA' and 'BSLA', De Houwer, 2018).

\subsubsection{Listeners}

The children's speech was judged for intelligibility by 80 native Dutch-speaking adult listeners between 18 and 53 years old who were unfamiliar with the children. All listeners were living in Flanders at the time they judged the data. Each listener judged the speech of only one child, because the listeners should not know which words and sentences were elicited and should be unfamiliar with the story. ${ }^{2}$ After the listening task, all listeners completed a short questionnaire about their language background (native language, knowledge of other languages, languages they come into contact with, familiarity with Turkish). None of the participants came into regular contact with Turkish-Dutch bilingual children. Six participants had just started a course of Turkish, but did not have much contact with Turkish speakers. All participants had some knowledge of other languages, most often English, French and/or German.

\subsection{Materials and tasks}

All children were tested with the Dutch intelligibility test PSv (Buekers et al., cf. Section 3). The test contains three tasks: a word production task, a sentence production task and a story-telling task. The lists of stimuli in all three tasks are provided in the appendix (Tables 1, 2 and 3).

\subsubsection{Task 1: Word production}

The first task is a picture-naming task aimed at eliciting 25 isolated target words. The child was shown a picture and was asked to repeat the word produced by the

2. The obvious disadvantage of having one listener transcribing the utterances of one child is that there are differences between listeners in the extent to which they are able to identify spoken utterances. However, asking listeners to mark the intelligibility of multiple children would not allow us to measure the extent to which the target utterances were actually intelligible, since the listeners would then be familiar with the target words, sentences and with the story. We therefore follow the method of having each listener transcribe the utterances of just one child, as described in the test's manual and used by Baudonck et al. (2009). In addition, the word production tasks of 13 children (21\%) were transcribed a second time, by 14 new raters. The results showed that for these children, exactly 39 out of 300 items (13\%) were unintelligible for both the first and the second group of raters, 21 of which were the same for both raters. The interclass correlation coefficient was .639 with a $95 \%$ confidence interval from .547 to .712 $(F(299,299)=.2 .77, p<.001)$, suggesting a moderate interrater agreement. 
experimenter. In order to familiarize the children with the task, the first five pictures were test trials.

\subsubsection{Task 2: Sentence production}

In the second task, children were shown 7 pictures and were asked to repeat a sentence describing the picture. Tasks 1 and 2 were taken by all children. Following the test guidelines, children below age 4 only did task 2 up till and including sentence no. 4; children aged 4 ; o or older did all 7 sentences. The younger children only repeated the first four sentences, because testing children on more complex sentences would shift the focus from speech intelligibility to the children's syntactic development.

\subsubsection{Task 3: Story-telling}

The third task is a narrative task: it contained four pictures which together form a short story and the children were invited to tell the story on the basis of the picture. The story was not told by the tester beforehand. This task was taken by a sample of 30 five- and six-year-old children (aged between 5;1 and 6;11), 15 of whom are monolingual and 15 of whom are bilingual.

\subsection{Procedure}

The children were recruited in six schools in Ghent, Belgium. They were all tested individually in a quiet room in their school, an environment that is familiar to them. The test lasted 10 to 15 minutes per child. Recordings were made with an audio recorder and later transferred to the computer. Children were rewarded with a sticker.

After the test, the stimuli were cut out of the long audio files with Praat (Boersma \& Weenink, 2018) and embedded in a PowerPoint presentation. Listeners received oral and written instructions: they were informed that they would hear words and sentences produced by young children. In order to minimize the effect of attitudinal factors, listeners were only told that the study was on speech intelligibility in children; the native language(s) of the child were not mentioned. No video recordings were made of the children during the task, so the listeners were only presented with the isolated audio utterances, again to minimize any effects of stereotypes. Listeners were instructed to click on the icon of a speaker to listen to the sound and then type the word or sentence they had understood. Each PowerPoint slide contained only the icon and the phrase 'type the word/ sentence' ('typ het woord/de zin'). It contained the audio file of only one word or sentence and listeners could listen maximally twice to the same audio file. They were asked to use headphones when performing the listening task. Each listening 
session lasted about 10 minutes. The participants were not paid for their participation.

\subsection{Coding}

The data were coded following the instructions of the intelligibility test PSv (Buekers et al., 2005). Listeners were instructed to write down what they thought the child intended to say. For instance, in the word production task, if the child says ${ }^{*}<$ slotel $>$ (nonword) instead of <sleutel $>$ ('key') and the listener understood $<$ sleutel $>$, this was coded as correct. In the sentence production task, each sentence contained a (different) number of target words the child had to produce in order to obtain the highest score. For instance, in the sentence $<$ het paard gaat een wortel eten $>$ ('the horse is going to eat a carrot'), the words paard ('horse'), wortel ('carrot') and eten ('to eat') needed to be understood by the listener to obtain full marks. Key words included both content and function words and in some sentences a mark was obtained when one of two keywords was included (see Table 2 in the appendix for details). A maximum number of marks was indicated for each of the seven sentences (sentence 1: 3 marks; sentence 2: 4 marks; sentence 3: 3 marks; sentences 4 to $7: 5$ marks). Similarly, for the story-telling task, each picture has a key idea, which needs to be conveyed in order to obtain full marks. For instance, picture 2 shows a monkey throwing away a banana skin (de aap gooit de schil weg). If the child says aap weggooien ('monkey throw away') and the listener understands 'the monkey has thrown away the skin', full marks are obtained, since the listener has understood the key idea (which is, of course, only possible if the word 'skin' was mentioned in the description of the previous picture). The maximum scores were 25 for the word production task, 15 for the sentence production task for all 7 sentences (children of 4 years or older), 7 for the first 4 sentences (children younger than 4 years) and 13 for the story-telling task. The raw scores obtained on each task were converted into average percentages for each child. This averaging is in line with the protocol of Buekers et al. (2005), and it allows for the pooling of the 4 sentences of the youngest children (i.e. younger than 4 years) with the 7 sentences of all older children.

\subsection{Analysis}

In order to answer our two research questions, we fitted a Linear Mixed-effects Model to the intelligibility scores of each child. The independent variables were age (a numeric variable counting the number of months), group (a nominal variable with the two categories: monolingual vs. bilingual) and task (a nominal variable with three categories: word, sentence and story). Both nominal variables 
were reference-coded with the first level as the reference level. We fitted a model with the three-way interaction between age, group and task, and subsequently refined it (i.e. we excluded non-significant terms). In this model the child was included as a random effect. We included a random intercept, since random slopes were not necessary: age and group do not vary for each child and task is a fixed effect in our analysis. This also means that centering or standardizing the age variable was not necessary. (A replication of the full analysis with a standardized age variable produced completely similar results.)

The analyses were done in the R software (R Core Team, 2020) with the lme4 package (Bates, Maechler, Bolker, \& Walker, 2015). The statistical significance of the terms was checked by means of ANOVA's with Type III tests (i.e. tests for whether the model fit would become significantly poorer if a certain term were deleted from the model), and the Results below will also give tables of the parameter estimates, standard errors, $t$ values, and $95 \%$ confidence limits. Moreover, the effects for the significant terms will be visualized with the effects package (Fox \& Weisberg, 2019).

\section{Results}

Analyses showed that the three-way interaction between age, group and task was not statistically significant, nor was the two-way interaction between age and group. Both interactions where therefore not part of the final model. The parameter estimates of the final model (with accompanying inferential results) are listed in Table 1.

The significant increase of intelligibility with age (as expressed by the positive coefficient 0,0041 for the main effect of age) confirms our expectations (Hypothesis 1a); the non-significance of the two-way interaction between age and group shows that this increase does not depend on language group, i.e. we found no evidence for Hypothesis $1 b$ that the increase in intelligibility as a function of age would be larger for the bilingual than for the monolingual children. For the monolingual children, the mean intelligibility of the three-year-old children is about $65 \%$ and rises to about $95 \%$ for the eldest, six-year-old children. For the bilingual children, the mean intelligibility ranges from about $40 \%$ for the threeyear-olds to $80 \%$ for the six-year-olds. However, there is a dependence between age and task, instead, as visualized in Figure 2.

Predicted intelligibility is positively influenced by the children's age and this effect is stronger for the sentence production task than for the word production task. The results show that the youngest children already attain a high score for the word production task (about 75\%) and the older children do not improve 
Table 1. Parameters estimates of the final model (with a two-way interaction between group and task and a two-way interaction between task and age)

\begin{tabular}{lccccc}
\hline & Estimate & Std. Error & t value & $\mathbf{2 , 5 \%}$ Conf. limit & $\mathbf{9 7 , 5 \%}$ Conf. limit \\
\hline (Intercept) & 0,6172 & 0,1049 & 5,882 & 0,4152 & 0,8192 \\
Bilingual & $-0,0703$ & 0,0411 & $-1,711$ & $-0,1495$ & 0,0088 \\
Sentence & $-0,6381$ & 0,1279 & $-4,991$ & $-0,8844$ & $-0,3918$ \\
Story & $-0,3498$ & 0,5270 & $-0,664$ & $-1,3633$ & 0,6662 \\
Age & 0,0041 & 0,0017 & 2,442 & 0,0009 & 0,0074 \\
Bilingual $\times$ Sentence & $-0,2208$ & 0,0501 & $-4,408$ & $-0,3173$ & $-0,1243$ \\
Bilingual×Story & $-0,2245$ & 0,0744 & $-3,017$ & $-0,3676$ & $-0,0806$ \\
Sentence $\times$ Age & 0,0094 & 0,0021 & 4,573 & 0,0055 & 0,0134 \\
Story $\times$ Age & 0,0041 & 0,0075 & 0,548 & $-0,0104$ & 0,0186 \\
(Random intercept) & 0,0930 & & & 0,0516 & 0,1263 \\
(Residual error) & 0,1579 & & & 0,1355 & 0,1767 \\
\hline
\end{tabular}

much anymore (to about 90\%), while for the sentence production task the youngest children start at a low score (about $40 \%$ ) and the different ages show a considerable improvement over time. For the story-telling task, there was no significant effect of age, but the age range for this task was much smaller than for the other two tasks, as only 30 children aged between 61 and 83 months $(5 ; 1$ to $6 ; 11)$ performed the story-telling task.

The two-way interaction between group and task addresses RQ2 and can be visualized in Figure 3.

Figure 3 presents the estimated intelligibility of the monolinguals vs. bilinguals in the three tasks. It demonstrates that there are no significant differences between the three tasks for the monolingual children, who overall have a mean intelligibility of around $80 \%$ for all three tasks. The bilingual children also have a mean intelligibility of about $80 \%$ for the word task, but for both the sentence task and the story-telling task their mean intelligibility is about $50 \%$. The difference between the bilingual children's sentence production task score and their word production task is statistically significant, as is the difference with the monolingual children's word and sentence production task scores. There is no significant difference between the sentence task and the story-telling task. The large confidence intervals in the results of the story-telling task are due to the low number of observations for that task. 


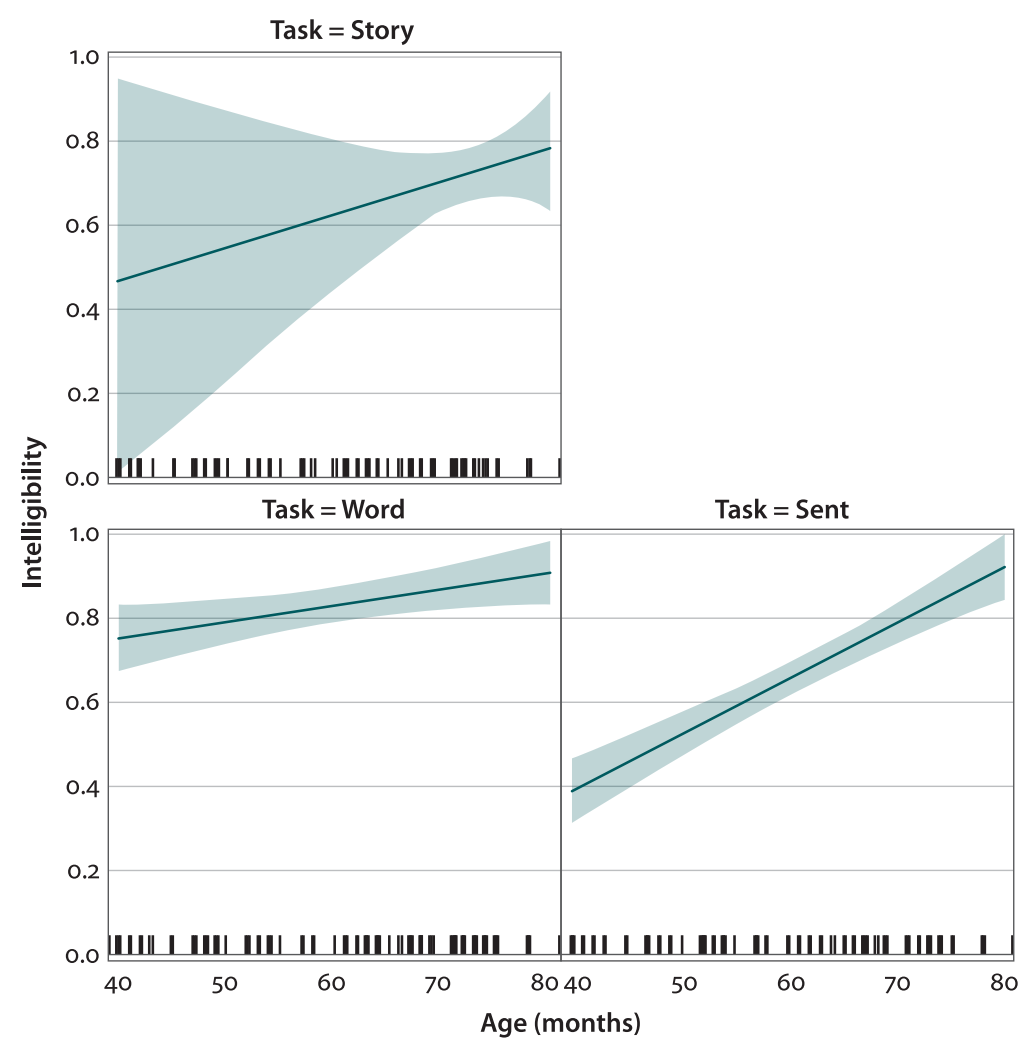

Figure 2. Estimated intelligibility as a function of age in the three tasks

\section{Discussion and conclusions}

The aim of this study was to characterize the speech intelligibility in a group of three- to six-year old bilingual Dutch-Turkish children in Flanders. We addressed two main research questions. The first question was whether intelligibility increases with age and if so, whether it increases to different extents for a group of monolingual Dutch and bilingual Dutch-Turkish children. The results revealed that intelligibility was affected by age, but showed no significant interaction between age and group so our analysis does not support the hypothesis that the difference in intelligibility between monolingual and bilingual children would be smaller for the older children. However, we found a significant interaction between age and task: children's intelligibility increased with age for a word production as well as a sentence production task, but much more so for the latter than for the former. There was no effect of age on the story-telling task, which was due to the low number of observations in only older children. The lack of evi- 


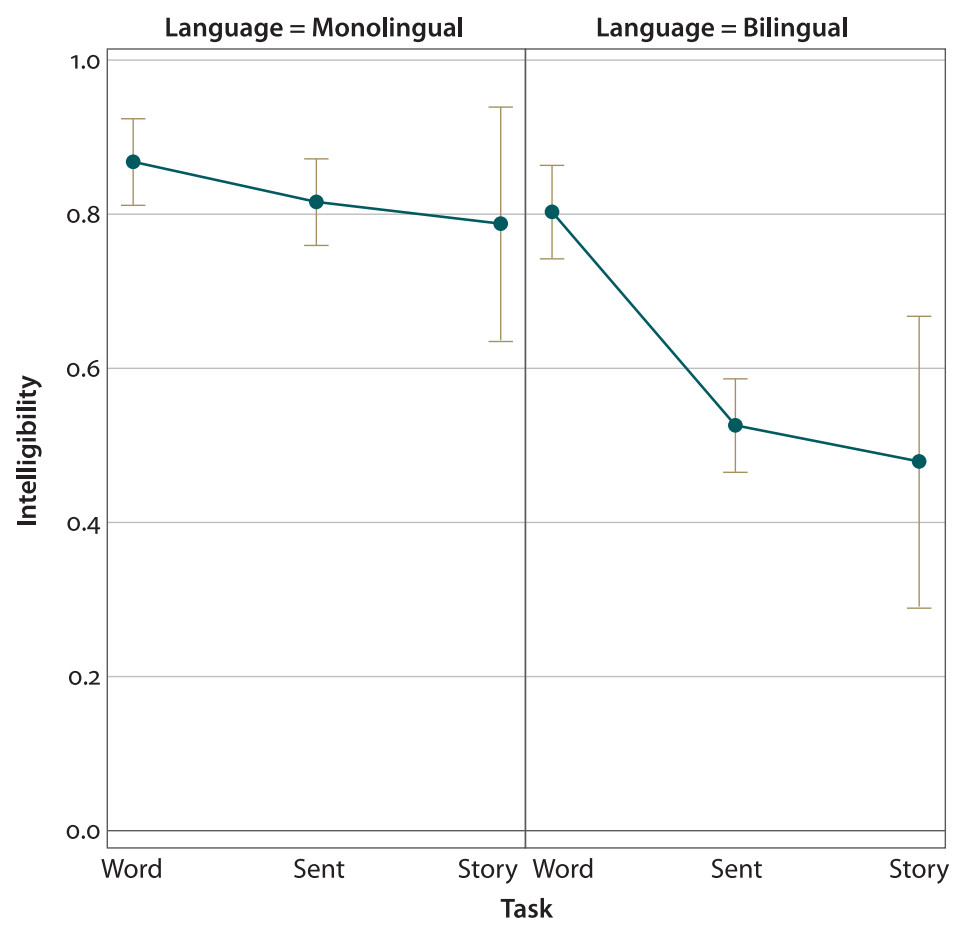

Figure 3. Estimated intelligibility in the three tasks and monolinguals vs. bilinguals for the full dataset

dence for an interaction between age and language group may be due to the fact that all three- to six-year-old children, independent of language background, are still developing their phonological system and their intelligibility greatly improves between the ages of three and six. As such, we see an increase in intelligibility as a function of age for monolingual as well as bilingual children: we do not so much observe an acceleration or deceleration in the bilingual children compared to the monolingual ones (see Section 2.2), but rather the bilingual children's intelligibility increases to the same extent as for the monolingual children. That this increase in intelligibility is especially strong for the sentence production task may be the result of the fact that the task was more cognitively demanding: as children had to repeat entire sentences, the children's larger lexicon and grammar as well as their processing abilities at age 6 compared to age 3 may explain the steep increase in intelligibility as a function of age.

The second research question we addressed was whether the tasks used to measure intelligibility affected the bilingual and monolingual children to different degrees. The results confirmed our hypothesis that the type of task differently impacted monolingual and bilingual children. In fact, the monolingual children 
reached intelligibility scores of $80 \%$ for all three tasks, while the bilingual children also reached $80 \%$ for the word production task, but scored lower for the sentence production and story-telling tasks (50\% in each case).

The results of the word production task suggest that, despite the bilingual children's years later (massive) exposure to the school language, Dutch, they have - even from the age of 3;0 - acquired the phonological system in Dutch to such an extent that their individual word productions are not less intelligible than those of monolingual children, who have been massively exposed to Dutch from birth. This does not imply that the children's Dutch speech may not show traces of a foreign accent. Following the Perceptual Assimilation Model (Best, 1995), the children may initially perceive the target Dutch sounds in terms of Turkish categories, leading to Turkish-accented Dutch speech. A detailed phonetic analysis of the produced data would be needed to confirm this, but even if some of the children's speech shows patterns of cross-linguistic phonetic transfer, these do not necessarily hinder intelligibility (cf. also Munro \& Derwing, 1995 on the relation between foreign accent and intelligibility)

Unlike the word production task, which most directly tests intelligibility, the sentence repetition task requires the child to process the sentence produced by the experimenter, remember it and repeat it. In other words, the child cannot just repeat the auditory form as in the word repetition task, but needs grammar and vocabulary in order to understand, remember and pronounce the sentence. Since most children in Flanders start attending preschool at age 2;5-3, bilingual three- to six-year old children have had limited exposure to the school language, Dutch. It is possible that the rather limited amount of exposure to Dutch which the bilingual children in the study had received was sufficient to be intelligible in a word production task, but that it was not yet sufficient to be intelligible when full Dutch sentences needed to be processed and repeated. The lower intelligibility of the bilingual children on the sentence production tasks may also partly be explained by the language background of the listener: the shared native language of the monolingual Dutch children and the Dutch-speaking listeners may have made it easier for the listeners to understand the monolingual children compared to the bilingual ones (cf. Hayes-Harb et al., 2008).

With this study we have shown that intelligibility in three- to six-year-old bilingual children increases with age to the same extent as for monolingual children and that there are significant task effects influencing the intelligibility scores by L1 adult listeners. The scores of intelligibility tests developed for monolingual children should hence be interpreted with caution, since the type of task may impact the bilingual children's performance differently compared to monolingual children. One avenue for further research is to test the children on their speech intelligibility in Dutch as well as Turkish, as assessed by adult Dutch and Turkish 
listeners, respectively. This would allow us to compare the children's intelligibility in their two languages and to map the development across children of different ages for different tasks.

\section{Funding}

This research was made possible thanks to a BOF grant from Ghent University to the first author (BOFSTG2018001201).

\section{Acknowledgements}

The authors wish to thank all children for their participation, the school heads and teachers for their cooperation, and the listeners for judging the auditory stimuli. Thanks are also due to Julie Camillo and Céline Cosaert for help with data collection and to Nele Baudonck for sharing her expertise on the intelligibility test used in this study.

\section{Declaration of conflicting interest}

The authors declare that there is no conflict of interest.

\section{References}

Altinkamis, F., \& Agirdag, O. (2014). Determinants of language use and attitudes among Turkish speakers in Flanders: A focus on generational difference. Bilig, 7o(3), 59-80. https://doi.org/10.12995/bilig.2014.7003

Babel, M., \& Russell, J. (2015). Expectations and speech intelligibility. Journal of the Acoustical Society of America, 137(5), 2823-33. https://doi.org/10.1121/1.4919317

Bates, D., Maechler, M., Bolker, B., \& Walker, S. (2015). Fitting linear mixed-effects models using lme4 . Journal of Statistical Software, 67(1), 1-48. https://doi.org/10.18637/jss.v067.io1

Baudonck, N.L.H., Buekers, R., Gillebert, S., \& Van Lierde, K. M. (2009). Speech intelligibility of Flemish children as judged by their parents. Folia Phoniatrica et Logopaedica, 61, 288-295. https://doi.org/10.1159/000235994

Bent, T. \& Bradlow, A. R. (2003). The interlanguage speech intelligibility benefit. Journal of the Acoustical Society of America, 114, 1600-1610. https://doi.org/10.1121/1.1603234

Best, C. T. (1995). A direct realist view of cross-language speech perception. In W. Strange (Ed.), Speech perception and linguistic experience: Issues in cross-language research, 171-204. Timonium, MD: York Press. 
Boerma, T., \& Blom, E. (2017). Assessment of bilingual children: What if testing both languages is not possible?. Journal of Communication Disorders, 66, 65-76. https://doi.org/10.1016/j.jcomdis.2017.04.001

Boersma, P. \& Weenink, D. (2018). Praat: Doing Phonetics by computer [computer programme], Version 6.0.36.

Buekers, R., Dekelver, J., \& Zoons, M. (2005). Beoordeling en meting Percentage Spraakverstaanbaarheid bij kinderen [Assessment and measurement Percentage Speech Intelligibility]. Logopedie, 17, 23-32.

Core, C., \& Hoff, E. (2012). Relationship of real and nonword production ability to vocabulary size in Spanish and English speaking toddlers. Paper presented at International Child Phonology Conference, June 4-6 2012. Minneapolis, MN.

Core, C., \& Scarpelli, C. (2015). Phonological development in young bilinguals: Clinical implications. Seminars in Speech and Language, 36(2), 100-108. https://doi.org/10.1055/s-0035-1549105

De Houwer, A. (2018). Input, context and early child bilingualism: implications for clinical practice. In A. Bar-On, \& D. Ravid (Eds.), Handbook of communication disorders: Theoretical, empirical, and applied linguistic perspectives (pp. 599-616). Berlin: Walter de Gruyter.

De Jong, J., Cavus, N., \& Baker, A.E. (2010). Language impairment in Turkish-Dutch bilingual children. In M. Topbas, \& M. Yavas (Eds.), Communication disorders in Turkish (pp. 290-302). Bristol: Multilingual Matters. https://doi.org/10.21832/9781847692474-018

De Smedt, H., Roeyers, H., \& Schelpe, L. (2017). Suggesties voor een handelingsgerichte diagnostiek van de taalontwikkeling bij meertalige kinderen [Suggestions for an actionoriented diagnosis of language development in multilingual children]. Signaal, 26, 4-20.

Fox, J., \& Weisberg, S. (2019). An R companion to applied regression (3rd ed.). SAGE: Thousand Oaks.

Dodd, B., Holm, A., Hua, Z., \& Crosbie, S. (2003). Phonological development: A normative study of British English-speaking children. Clinical Linguistics and Phonetics, 17(8), 617-643. https://doi.org/10.1080/0269920031000111348

Hayes-Harb, R., Smith, B.L., Bent, T., \& Bradlow, A. R. (2008). The interlanguage speech intelligibility benefit for native speakers of Mandarin: Production and perception of English word-final voicing contrasts. Journal of Phonetics, 36(4), 664-679. https://doi.org/10.1016/j.wocn.2008.04.002

Hoff, E. (2006). How social contexts support and shape language development. Developmental Review, 26, 55-88. https://doi.org/10.1016/j.dr.2005.11.002

Jenkins, J. (2000). The phonology of English as an international language, Oxford: Oxford University Press.

Kang, O., Thomson, R.I., \& Moran, M. (2018). Empirical approaches to measuring the intelligibility of different varieties of English in predicting listener comprehension. Language Learning, 68(1), 115-146. https://doi.org/10.1111/lang.12270

Kent, D. R., \& Miolo, G. (1994). The intelligibility of children's speech. American Journal of Speech-Language Pathology, 3, 81-95. https://doi.org/10.1044/1058-0360.0302.81

Munro, M., \& Derwing, T. (1995). Foreign accent, comprehensibility, and intelligibility in the speech of second language learners. Language Learning, 45(1), 73-97. https://doi.org/10.1111/j.1467-1770.1995.tboog63.x 
Prezas, R.F., Hodson, W.B., \& Schommer-Aikins, M. (2014). Phonological assessment and analysis of bilingual preschoolers' Spanish and English word productions. American Journal of Speech-Language Pathology, 23, 176-185. https://doi.org/10.1044/2013_AJSLP-12-0132

Rajadurai, J. (2007). Intelligibility studies: a consideration of empirical and ideological issues. World Englishes, 26(1), 87-98. https://doi.org/10.1111/j.1467-971X.2007.00490.x

$\mathrm{R}$ Core Team. (2020). R: A language and environment for statistical computing. R Foundation for Statistical Computing, Vienna, Austria. URL https://www.R-project.org/

Scarpelli, C., \& Core, C. (2014). Predictors of bilingual speech production in English-Spanish speaking preschoolers at 48 months. Poster presented at Annual Convention of the American Speech-Language-Hearing Association; November 20-22 2014. Orlando, FL.

Thordardottir, E., Rothenberg, A., Rivard, M.-E., \& Naves, R. (2006). Bilingual assessment: Can overall proficiency be estimated from separate measurement of two languages? Journal of Multilingual Communication Disorders, 4(1), 1-21. https://doi.org/10.1080/14769670500215647

Vasandani, V., Babel, M., \& Munson, B. (2018). Investigating the influence of listener attitudes and expectations on the intelligibility of Hindi English. Journal of the Acoustical Society of America, 143, p. 1924. https://doi.org/10.1121/1.5036281

\section{Appendix Stimuli}

Table 1. Subtest 1: Words

\begin{tabular}{|c|c|c|c|c|c|}
\hline No. & Original Dutch & English translation & No. & Original Dutch & English translation \\
\hline 1. & bal & ball & 14. & boom & tree \\
\hline 2. & mes & knife & 15. & schoen & shoe \\
\hline 3. & aap & monkey & 16. & huis & house \\
\hline 4. & bad & bath & 17. & lepel & spoon \\
\hline 5. & olifant & elephant & 18. & pop & doll \\
\hline 6. & telefoon & telephone & 19. & boek & book \\
\hline 7. & bed & bed & 20. & bloem & flower \\
\hline 8. & eten & food & 21. & tafel & table \\
\hline 9. & trein & train & 22. & kat/poes & cat \\
\hline 10. & boot & boat & 23. & slapen & to sleep \\
\hline 11. & banaan & banana & 24. & toilet/wc & toilet \\
\hline 12. & muts & hat & 25. & duim & thumb \\
\hline 13. & hond & $\operatorname{dog}$ & & & \\
\hline
\end{tabular}


Table 2. Subtest 2: Sentences

\begin{tabular}{|c|c|c|}
\hline No. & Original Dutch & English translation \\
\hline 1. & Het hondje is stout geweest. & The dog has been naughty. \\
\hline 2. & De schoenen zitten in de tas. & The shoes are in the bag. \\
\hline 3. & Het paard gaat een wortel eten. & The horse is going to eat a carrot. \\
\hline 4. & $\begin{array}{l}\text { Deze meneer heeft een baard, die meneer } \\
\text { heeft geen baard. }\end{array}$ & $\begin{array}{l}\text { This gentleman has a beard, that } \\
\text { gentleman has no beard. }\end{array}$ \\
\hline 5. & $\begin{array}{l}\text { Het kindje zingt een liedje aan de } \\
\text { telefoon. }\end{array}$ & The child is singing a song on the phone. \\
\hline 6. & Op mijn pyjama staan mooie bloemen. & $\begin{array}{l}\text { There are beautiful flowers on my } \\
\text { pyjamas. }\end{array}$ \\
\hline 7. & $\begin{array}{l}\text { Met die sleutel kan je de koffer } \\
\text { openmaken. }\end{array}$ & With this key you can open the suitcase. \\
\hline
\end{tabular}

Note: A mark was gained for the production of a word in bold and for the production of one of two underlined words in a sentence.

Table 3. Subtest 3: Story-telling

\begin{tabular}{|c|c|c|}
\hline No. & Original Dutch & English translation \\
\hline 1. & $\begin{array}{l}\text { De man/de jongen/het kindje geeft een } \\
\text { banaan aan de aap (in de kooi). }\end{array}$ & $\begin{array}{l}\text { The man/boy/child gives a banana to } \\
\text { the monkey (in the cage). }\end{array}$ \\
\hline 2. & De aap eet de banaan (op). & The monkey eats the banana. \\
\hline 3. & De aap gooit de schil/de banaan weg. & The monkey throws away the banana. \\
\hline 4. & $\begin{array}{l}\text { De man/de jongen valt/glijdt uit over de } \\
\text { schil/de banaan. }\end{array}$ & $\begin{array}{l}\text { The man/boy falls down/slips on the } \\
\text { banana (skin). }\end{array}$ \\
\hline
\end{tabular}

\title{
Address for correspondence
}

\author{
Ellen Simon \\ Ghent University \\ Department of Translation, Interpreting and Communication \\ Groot-Brittanniëlaan 45 \\ 9000 Gent \\ België \\ ellen.simon@UGent.be \\ iD https://orcid.org/oooo-00o2-5095-8693
}




\section{Co-author information}

Evelien D'haeseleer

Ghent University

Department of Rehabilitation Sciences

Section Speech Language Pathology and

Audiology

Evelien.DHaeseleer@UGent.be

Feyza Altinkamis

Ghent University

Department of Translation, Interpreting and

Communication

feyza.altinkamis@UGent.be

\section{Publication history}

Date received: 28 May 2019

Date accepted: 2 December 2020

Published online: 8 January 2021
Koen Plevoets

Ghent University

Department of Translation, Interpreting and

Communication

Koen.Plevoets@UGent.be

iD https://orcid.org/oooo-0oo3-3889-1809 